\section{UNIVERSITY \\ OF DEBRECEN}

FACULTY OF

HeALTH

NYÍREGYHÁZA

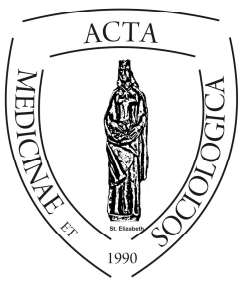

ACTA

MedSoc

VOLUME 6.

2015

\title{
Socio-psychological personality traits as a precondition for social inclusion
}

\author{
Vladimíra Lovasová, Jana Miňhová \\ Psychology Department \\ Faculty of Education \\ University of West Bohemia
}

\begin{abstract}
The paper presents partial results of the research realized in 2015 at the Psychology Department FPE University of West Bohemia. The aim of the research was to analyze the relationship between subjective perception of social inclusion and social and psychological characteristics that a person uses while interacting in a social group. The research sample tested pupils of 1st and 2nd levels of elementary schools of common type. To collect data we used standardized psychometric test B-J.E.P.I. and Picture Projective technique. The results suggest that dominant behaviour generally boosts subjective perception of social inclusion. The relationship between emotional dependency on the group and subjectively perceived social inclusion is significant only in second level of elementary school. Visible relationship between social inclusion and the degree of extraversion has not been shown.
\end{abstract}

Keywords: socio-psychological personality traits, dominance, extroversion, psychoticism, social inclusion 


\section{Introduction}

The research that we present was conducted by a team of psychologists at the University of West Bohemia. It is based on the study of Kaukiainen et al (2002) in which the negative correlation between social intelligence and social exclusion, victimization, etc. was confirmed. Another research, analyzed the relationship between social exclusion and the forms of dominance which a pupil socially enforces (Tjeert, 2011). Our team was trying to cover all the basic sociopsychological characteristics of a pupil. According to Ŕíčan (2010) sociopsychological characteristics are applied in contact with people and are used in most social roles. We are mainly focussing on social intelligence, extroversionintroversion, dominance-submissiveness and emotional dependency-autonomy. Thurstone defined social intelligence as the ability to solve various social problems effectively. Thorndike pointed out that social intelligence was relatively independent of general intelligence (Nakonečný, 1997). According to Miňhová (2007) individuals with a good level of social intelligence are empathic, have a memory for faces, are tactful and able to deal with people. Empathy means to listen to feelings and emotions. Emotional ability encompasses abilities such as recognizing one's own emotions, coping with emotions, the ability to motivate oneself, perceptiveness to the emotions of others and the art of interpersonal relation (Liberská, Kosíková, 2014). Thuston's concept of social intelligence is essentially identical to the concept of emotional intelligence by Goleman (2011).

Dominance, as one of the styles of social behaviour, has been described by Argyle. Dominance is a tendency to manage the situation and other people (Nakonečný, 1998). We do not intend to define a well-known personality trait like extraversion or introversion, but rather focus on the category of "dependency and autonomy". For emotionally dependent pupils their class is very important since it is primarily an emotional dependency to be in a social group. Their self-esteem depends on their social status in class. They are very intrinsically motivated to act in a manner that integrates them into the group.

The aim of our research was to analyze the relationship between subjective feelings of social inclusion and social and psychological characteristics that a pupil uses while interacting in the classroom. 


\section{Design of research}

The research sample comprised a total of 300 pupils from three elementary schools involving 157 boys and 143 girls, 170 first-grade pupils aged $6-11$ years and 130 second-grade pupils aged 11-15 years. The research sample was assembled from pupils of common elementary school to correspond with demographic curve. An important selection criterion was the willingness of schools to collaborate.

The data were collected by using standardized psychological test B-J.E.P.I and projective technique. During the data processing the methods of relative frequency, chi-square test and Fisher tests were used.

Limits research arise primarily from a number and specificity of used methods. Projective methods are considerably subjective and it depends on the erudition and experience of diagnostician. They more expose problems, conflicts, needs and interests than visible signs (Šnýdrová, 2008, s.22).

Eysenck's Personality Questionnaire was adapted by Juřicová (Senka, 2004) for children to Czech conditions. This questionnaire was used to measure the degree of extroversion and psychoticism. Psychoticism (P) in Eysenck's concept measures the level of solitude and insensitivity. Children with a high $P$ value are solitary, cruel and heartless. They have no compunction, no empathy, can be aggressive and malicious. In our research we have interpreted the higher value of psychoticism as a lack of social intelligence.

In the following projective picture we were looking for signs of social inclusion-exclusion, dominance-submissiveness and dependency-autonomy. Pupils were given a picture with the following instructions: Look carefully at the picture in front of you and count all the figures. Note that each of the figures is located elsewhere doing different things and having some facial expression. Imagine that the tree is your classroom and the figures are children in the class. If any of the characters reminds you some of your classmates, add his or her name to the figure. You may put more than one name to the figure. When you have finished, draw a circle to demonstrate yourself (according to how you feel in the classroom). 


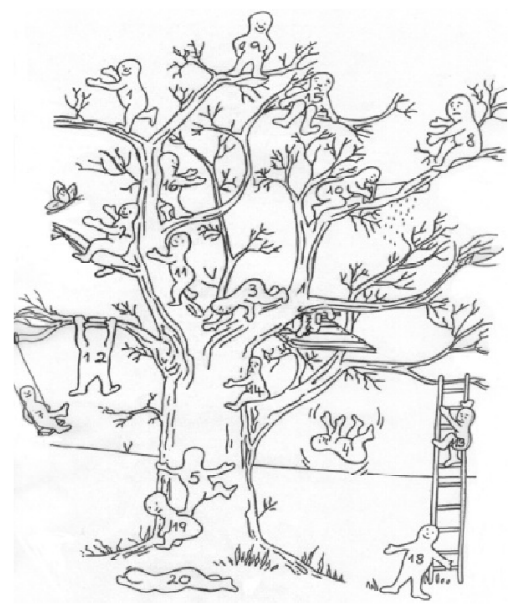

Picture No. 1 - Projective technique

To assess the task we used Leary's scheme of interpersonal analysis. Sorting criterions were the location either on the right or the left, emotions that the figure provokes, the position on the top of the tree and the little figure that watches or can watch the tree trunk. As a matter of fact this technique can map the pupils' subjective feelings only.

\section{Socio-psychological characteristics of pupils}

\section{Social inclusion / exclusion total (\%)}

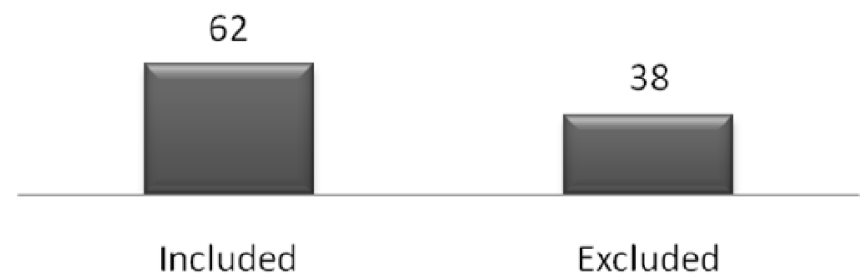

Graph No. 1 - Subjective perception of social inclusion/exclusion - total.

The graph No. 1 shows that $38 \%$ of the pupils feel socially excluded. 


\section{Social inclusion / exclusion in school classes (\%) \\ $\leadsto$ Included $\rightarrow$-Excluded}

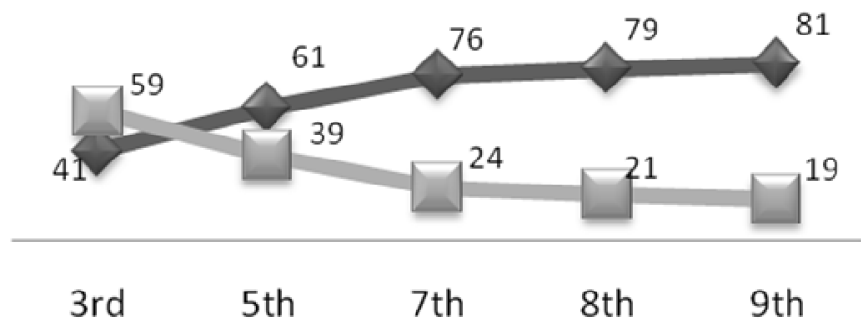

Graph No. 2 - Perception of social inclusion / exclusion among pupils of different grades.

The line graph (Graph No. 2) shows that over the elementary school years, the number of excluded pupils is falling while the number of included pupils is rising. This can be considered as a positive phenomenon, because the incorporation into the social group helps to create positive self-concept.

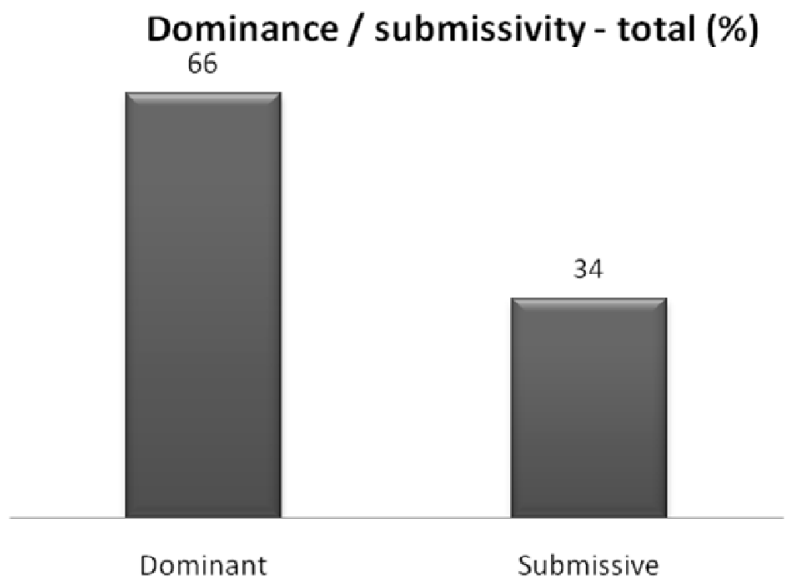

Graph No. 3 - Subjective perception of dominance / submissivity - total. 
$66 \%$ of the pupils consider themselves rather dominant. (Graph No. 3)We found no significant difference between boys and girls. We found that there is a minor proportion of subjective dominance in the 1st grade of elementary school, and by the 8th grade the dominance is significantly falling. Pupils are around 14 at that time, therefore the decrease must be related to developmentally conditioned social insecurity. Membership of a group treated as a reference group is particularly important in view of the process of identity development and the emergence of its social and personal aspects - the differentiation of „I“, its separation and ultimate integration (Farnická, Liberská, 2014).

\section{Dependence / autonomy - total (\%)}

56

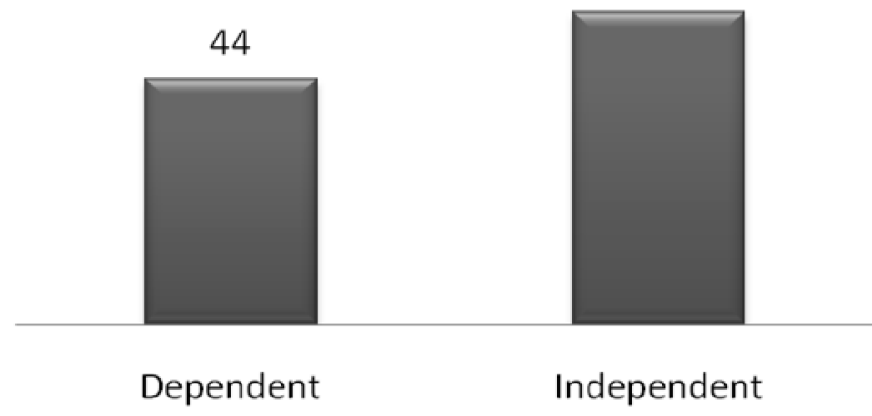

Graph No. 4 - Subjective perception of emotional dependence / autonomy - total.

Less than half of the pupils feel emotional dependency in the classroom as a social group. (Graph No. 4) The difference between boys and girls is not significant. In this category a significant difference was found between the 1st and 2 nd grades, which is probably a developmental phenomenon, too. On the first level there is the basic reference group family, while on the second one it is already a peer group. The increasing importance of the peer group is particularly visible in the period of transition in the second stage of primary school. The moderate decline may be related to the fact that teens gradually extend their social structure; emotionally they may be more identified with their sports team or a group of friends in the place where they live. 


\section{Extraversion / introversion - total}

(\%)

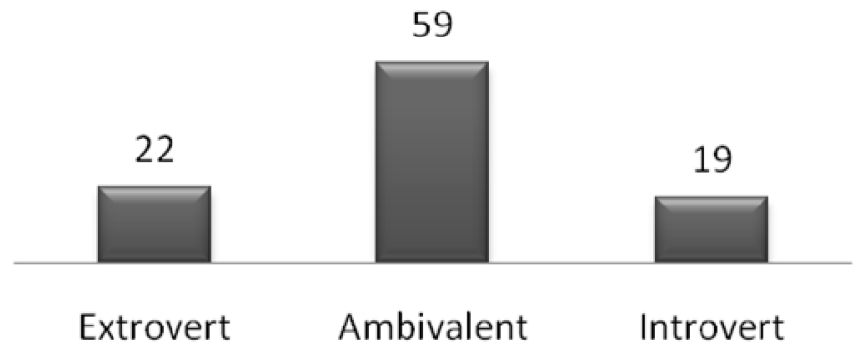

Graph No. 5 - Extraversion / introversion - total.

The Graph No. 5 shows that the rate for ambivalent students is much higher than that of the extrovert and introvert ones. When examining this factor we started from the age norms in the test, therefore we did not notice the difference between the 1 st and 2 nd grades of elementary school. No clear differences were shown between boys and girls.

\section{Degree of psychoticism - total (\%)}

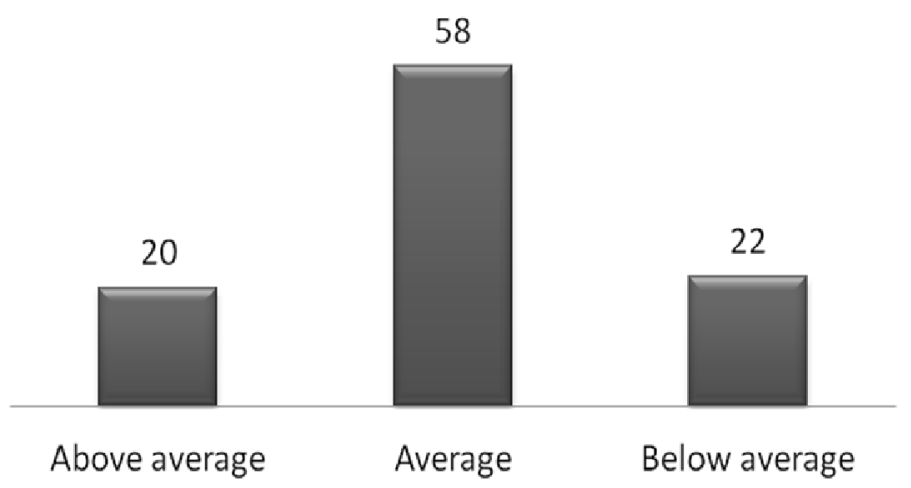

Graph No. 6 - Degree of psychoticism - total. 
We have also classified the categories of psychoticism by the standard test and the results can be seen in the Graph 6. Pro-social orientation and social intelligence indicate low averaged psychoticism.

\section{Psychoticism and gender (\%)}

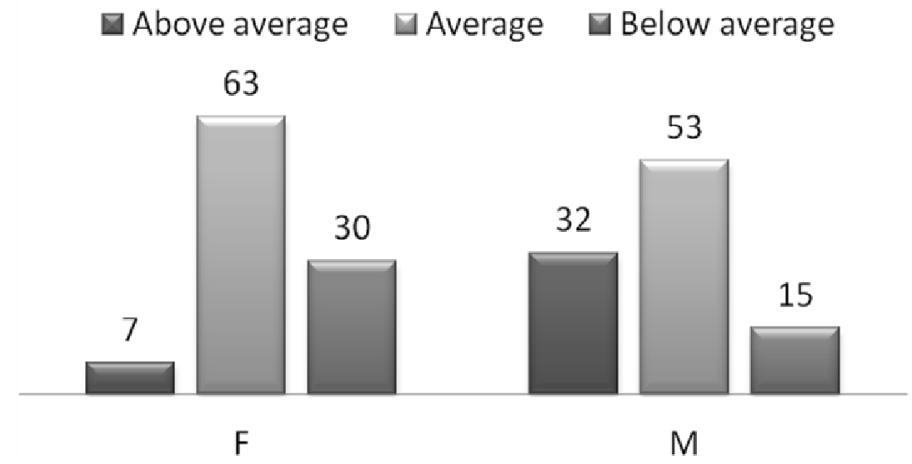

Graph No. 7 - Degree of psychoticism and gender.

The differences between girls and boys may generally indicate higher tendency to empathy in women. (Graph No. 7)The development aspect has not been manifested.

\section{The relationship between socio-psychological characteristics of pupils and their subjective feelings of social inclusion}

In the following section we present a statistically significant relationship between the observed socio-psychological characteristics of pupils and the perception of social inclusion.

There is nearly a $20 \%$ difference among socially included and socially excluded pupils in the category of dominance. The result suggests that dominant behaviour generally boosts social inclusion. The statistical significance of the relationship of these factors has been confirmed at a level of $0.1 \%(\mathrm{G}=10,972$, $\chi(1-\alpha)$; $\mathrm{df}=10,828)$. This relationship is especially true for the 1 st stage of primary school, at which the demonstrated statistical dependence is on the $0.1 \%$ 
level of significance $(\mathrm{G}=17,5057, \chi(1-\alpha) ; \mathrm{df}=10,828)$. The need to be dominant for social inclusion is especially true for girls in the first grade.

\section{Relationship between social inclusion and dominance (\%)}

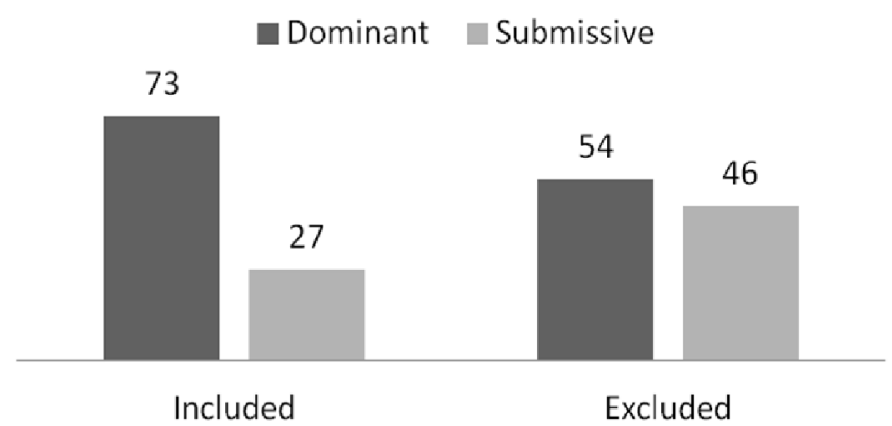

Graph No. 8 - Subjective perception of social inclusion and dominance.

\section{Relationship between social inclusion and emotional dependency - 2nd grade (\%)}

$\square$ Dependent $\square$ Independent

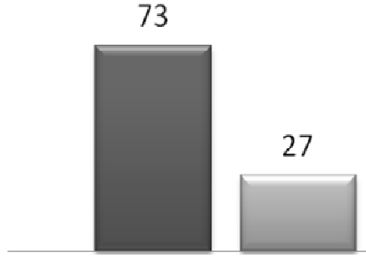

Included

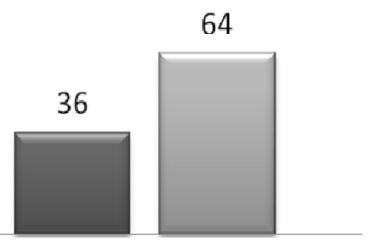

Excluded

Graph No. 9 - Subjective perception of social inclusion and emotional dependence.

The relation of emotional dependency and perceived social integration may appear a natural group process, but they take place up to the second level of school. The high level of dependence has been confirmed particularly among boys $(\mathrm{G}=13,029, \chi(1-\alpha) ; \mathrm{d} f=10,828,0,1 \%)$. Emotional independence of the members brakes cohesion of every social group. 


\section{Relationship between social inclusion and level of extraversion (\%)}

$\square$ Extrovert $\square$ Ambivalent $\square$ Introvert

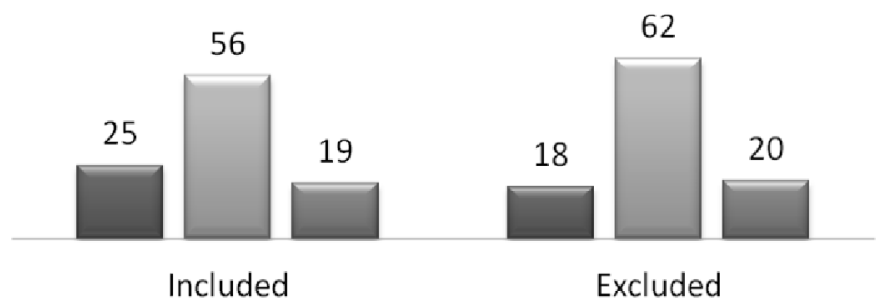

Graph No. 10 - Subjective perception of social inclusion and the degree of extraversion.

Visible relationship between social inclusion and the degree of extraversion has not been shown in our sample. The result is essentially expected because extraversion is largely genetically determined predisposition, therefore it is less variable.

\section{Relationship between social inclusion and degree of psychoticism (\%)}

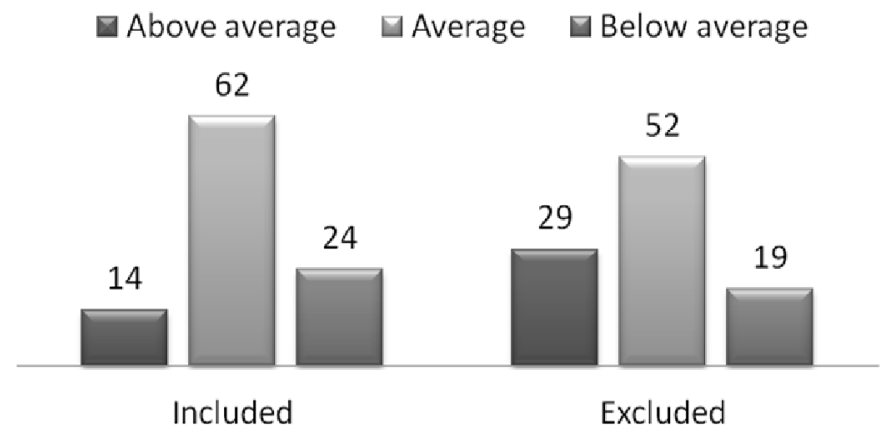

Graph No. 11 - Subjective perception of social inclusion and the degree of psychoticism.

The relation of social inclusion and psychoticism was shown but the interdependence is around $1 \%(\mathrm{G}=12,349, \chi(1-\alpha) ; \mathrm{d} \mathrm{f}=9,21)$. A specific social sensitivity to others is prized, especially on the second level of primary school. The category of the excluded pupils did not include any pupils with a low 
psychoticism. The higher level of psychoticism at the second stage is socially excluded, though at the first stage it was not visible.

\section{Conclusion}

Pupils are not just passive recipients of social inclusion or exclusion in the classroom, but they can actively participate in the extent of their integration. In terms of monitored factors, in general, the most important are dominant behaviour and lower levels of psychoticism.

From a development perspective it is the dominance that is mostly shown among primary school pupils, especially among girls. According to Říčan (2010) the dominance arises from innate aggressive tendencies, but is influenced by social learning.

The emotional dependence on the group and lower degree of psychoticism, which corresponds with social intelligence, are important for social inclusion of adolescents. It is possible to develop theese in the process of social learning too. Emotional dependence on the group is related to the intrinsic motivation for social inclusion. There is no activity without motivation. Especially the boys at the second levels of school should actively strive for their social inclusion, for example through the imitation of acceptable negotiation. Otherwise, they act as uncommitted and thereby blocking group inclusive processes.

Responsibility for social inclusion can not only be transferred to the classroom as a social group, but the socially excluded pupil must be actively involved in this process. Therefore, teachers should focus not only on working with the class as a whole, but also individually work with socially excluded pupils to help them develop their social and psychological characteristics.

For socially excluded pupils it could be useful to use the socio-psychological training in which they learn how to interact more dominantly and more empathetically.

Teachers would be able to explain them what is and is not tactful negotiations based on the analysis of concrete situations. They could also help them to find a suitable model for imitation among popular students.

We are currently preparing a program of social and psychological development for socially excluded pupils and we will continue to monitor their perception of social inclusion. 


\section{Literature}

1. Farnická, M. \& Liberská, H. (2014). A child of Many Worlds: A New Meaning of Acculturation. Child of Many Worlds: Focus on the Problem of Ethnic Minorities. Franfurt: Peter Lang GmbH, pp.213-225.

2. Goleman, D. (2011). Emoční inteligence. Praha: Metafora.

3. Kaukiainen, A., Salmivalli, C., Lagerspetz, K., Tamminen, M., Vauras, M., Mäki, H. and Poskiparta, E. (2002), Learning difficulties, social intelligence, and self-concept: Connections to bully-victim problems. Scandinavian Journal of Psychology, 43: 269-278. doi: 10.1111/14679450.00295

4. Kosíková,V. \& Liberská, H. (2014). The problem of Minorities as a Subject of Intercultural Psychology. Child of Many Worlds: Focus on the Problem of Ethnic Minorities. Franfurt: Peter Lang GmbH, pp.27-45.

5. Miňhová, J., Holeček, V., Prunner, P. (2007). Psychologie pro právníky. Plzeň: Aleš Čeněk.

6. Nakonečný, M. (1997). Encyklopedie obecné psychologie. Praha: Academia.

7. Nakonečný, M. (1998). Základy psychologie. Praha: Academia.

8. Ŕíčan, P. (2010). Psychologie osobnosti. Praha: Grada Publishing.

9. Senka, J. (2004). Osobnostní dotazník pro děti : B-JEPI. Praha: Psychodiagnostika, s.r.o.

10. Šnýdrová, I. (2008). Psychodiagnostika. Praha: Psyché.

11. Tjeert O., Frits A. Goossens, Marjolijn M. Vermande, Elisabeth A. Aleva, Matty van der Meulen. (2011). Bullying as strategic behavior: Relations with desired and acquired dominance in the peer group .Original Research Article. Journal of School Psychology, Volume 49, Issue 3, pp. 339-359.

Mgr.Vladimíra Lovasová, Ph.D.

Psychology Department

Faculty of Education

University of West Bohemia

lovasova@kps.zcu.cz

Doc. PhDr. Jana Miňhová, CSc.

Psychology Department

Faculty of Education

University of West Bohemia

jminhova@kps.zcu.cz 
